\title{
Early prenatal ultrasonographic diagnosis and follow up treatment of a giant abdominal hemangioma: a rare case report
}

\author{
Dinu-Florin Albu ${ }^{1}$, Cristina-Crenguta Albu ${ }^{2}$, Andrei Oncescu ${ }^{3}$, Stefan-Dimitrie Albu ${ }^{4}$ \\ ${ }^{1}$ Dr. Dinu-Florin Albu, Ass. Professor, Obstetrics \& Gynecology and Medical Genetics, Expert in Maternal Fetal \\ Ultrasound and Maternal-Fetal Medicine, ${ }^{2}$ Dr. Cristina-Crenguta Albu, Ass. Professor, Ophthalmology and Medical \\ Genetics, ${ }^{3}$ Dr. Andrei Oncescu, MD Obstetrics \& Gynecology, ${ }^{4}$ Stefan-Dimitrie Albu, Medical Student. \\ All are affiliated with University of Medicine and Pharmacy "Carol Davila“, Bucharest, Romania
}

Address for Correspondence: Dr. Cristina-Crenguta Albu, Address- 27A, Catedrei Street, 1st District, Bucharest, Romania. E-mail: stevealbu@yahoo.com

\begin{abstract}
Abstact
We report the rare case of a fetus diagnosed in utero as early as 16 weeks with a growing lateral abdominal wall hemangioma. Ultrasonography confirms space occupying lesion and Colour Doppler ultrasound examination proves the vascularity of lesion. Fetal MRI was performed at 27 weeks and confirmed the localization, neither of the internal organs being affected and no other hemangiomas being detected. The baby was delivered at 36 weeks after premature rupture of membranes and transferred to the pediatric department. Angiography was performed and after further analysis the baby was referred for surgical treatment. Surgery was a success and the baby came for the routine 6 months check up.
\end{abstract}

Key words: Hemangioma, Abdominal wall, Prenatal, Ultrasonographic, Diagnosis

\section{Introduction}

Vascular anomalies are encompassed in two major categories: vascular tumors, which are proliferative endothelial lesions, such as hemangiomas, and vascular malformations, which are developmental aberrations of hematic or lymphatic vessels $[1,2]$.

Haemangioma are common benign vascular soft tissue tumour. The most frequent sites of haemangiomas are extremities, head and neck. Exact cause of haemangioma is unknown.

Vascular tumors of the abdominal wall, benign congenital malformations that may cause pain or cosmetic disfigurement are very rarely [3, 4]. The abdominal wall is a quiet rare location of haemangionas [4].

Abdomen hemangiomas may occur in such atypical locations and can have such unusual features that they cause significant diagnostic dilemma $[5,7]$.

Manuscript received $30^{\text {th }}$ September 2016

Reviewed: $12^{\text {th }}$ October 2016

Author Corrected: $20^{\text {th }}$ October 2016

Accepted for Publication $31^{\text {st }}$ October 2016
Hemangiomas of the abdominal wall can be isolated congenital vascular tumors or associated with other

vascular malformations [4]. Very rarely, hemangiomas can occur in the inguinal canal along the spermatic cord $[5,6]$.

\section{Case Report}

We report a case of a 36 year old Caucasian woman, who was referred at 16 weeks' gestation for routine prenatal scan. There was no family history of congenital anomalies and chromosomal defects. The couple was not consanguineous and had normal general health.

\section{Methods}

Routine ultrasonography at 16 weeks of pregnancy, double and triple marker test (AFP, uE3 and hCG), selective ultrasonography for detection of fetal abnormalities, Colour Doppler ultrasound examination, 3D and 4D live scan with Voluson Echograph E8, amniocentesis, QF-PCR, fetal karyotype and fetal MRI, were performed. 


\section{Results}

Double test was found normal at that time. The biometry of the fetus was normal for his gestational age. Triple test was not sensitive to the presence of a possible trisomy. Ultrasound examination at 16 weeks of gestation revealed a single fetus with: lateral abdominal wall soft tissue mass. (Figure 1, Figure 2). The visualization of pulsating Doppler signals and the smooth and sonoluscent aspect of the tumor was highly suggestive for the diagnosis: giant lateral abdominal wall hemangioma. (Figure 3, Figure 4).

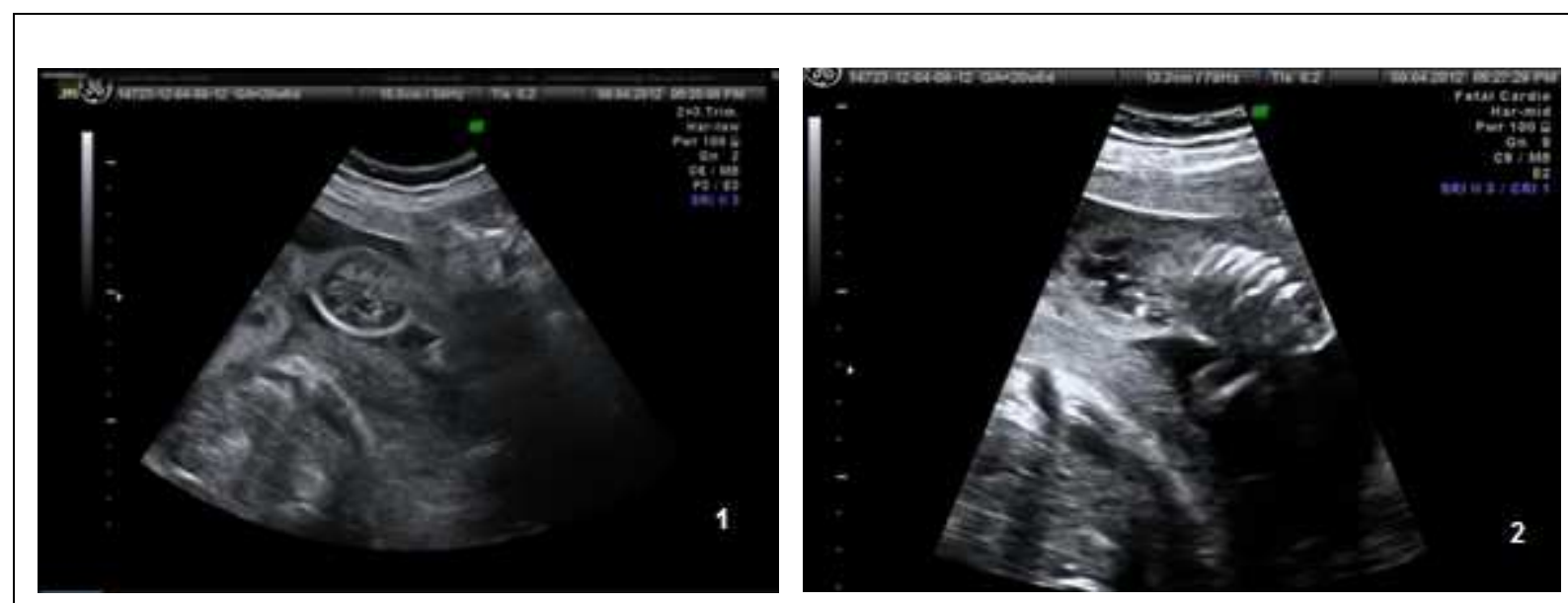

Figure-1 and 2: Initial ultrasound examination of the fetal abdomen revealed a lateral abdominal wall soft tissue mass.
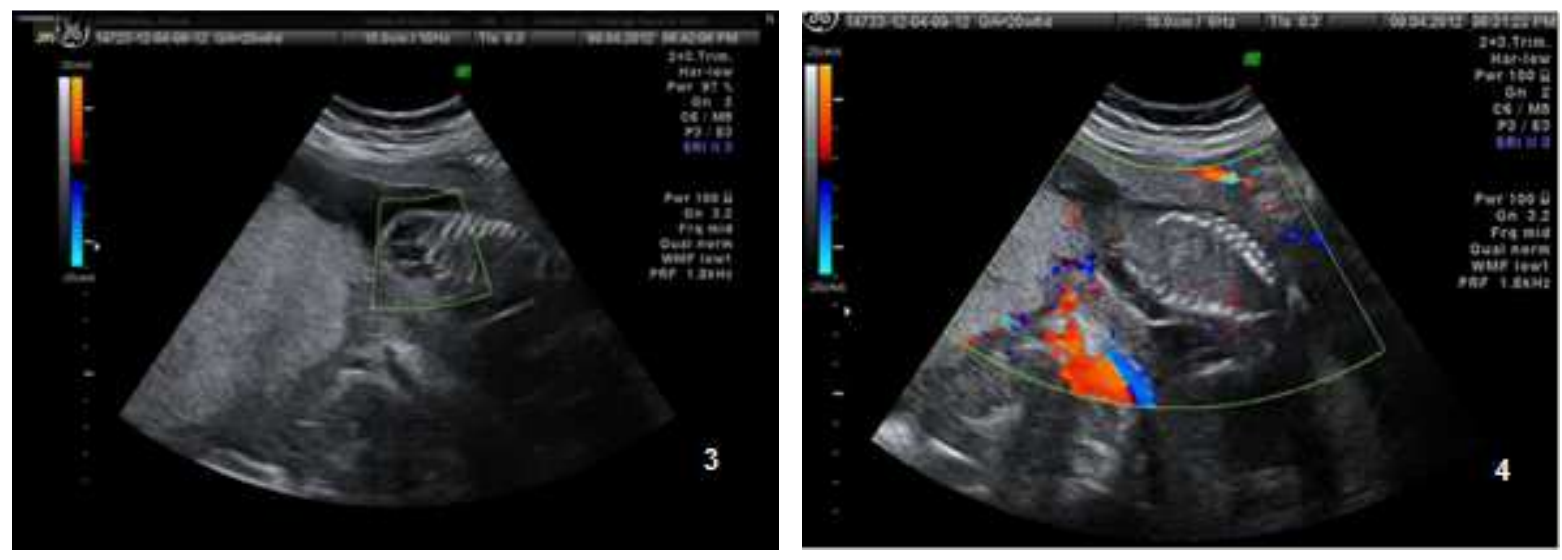

Figure-3 and 4: 3D Power Doppler HD ultrasound examination of the fetal abdomen revealed a giant lateral abdominal wall hemangioma.

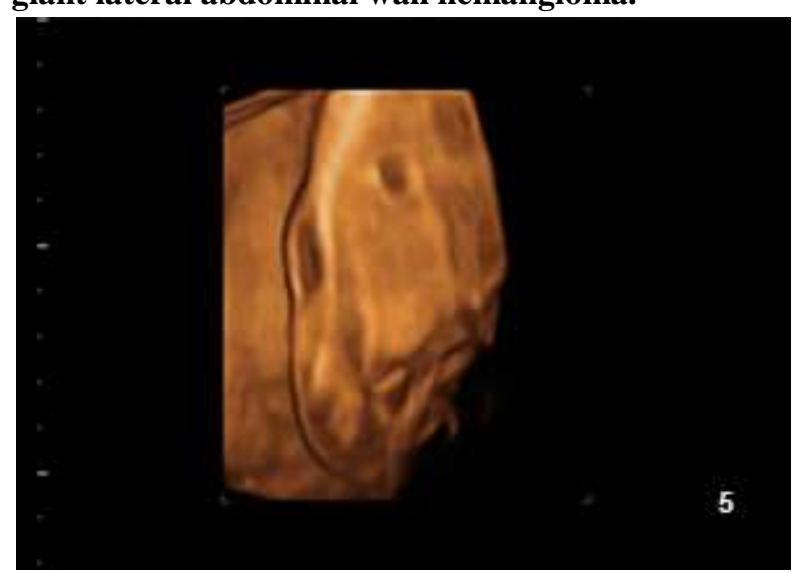

Figure -5: 3D reconstruction of hemangioma.

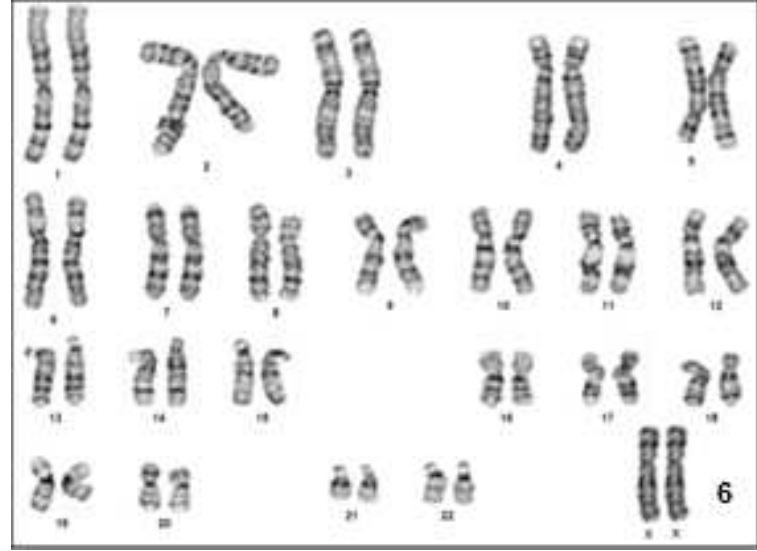

Figure- 6: Female normal karyotype: 46, XX. 
Amniocentesis was performed in order to exclude chromosomal abnormalities and was found normal: female normal karyotype: 46, XX (Figure 6).

Fetal MRI was performed at 28 weeks of gestation and confirmed the localization, neither of the internal organs being affected and no other hemangiomas being detected.

Follow up scans showed the increase of the tumor size as the pregnancy advanced and the apparition of polyhidramnios.

The fetus was delivered at 37 weeks through cesarean section after premature rupture of membranes. After, the baby was transferred to the Department of Neonatology. After further investigations the baby was referred for surgical specific treatment. Surgery was a success and the baby came for the routine 6 months check up.

\section{Discussion and Conclusions}

The muscles and fascial layers of the abdominal wall protect intraperitoneal contents and abdominal structures are extended to the retroperitoneal space [8].

The cause of hemangiomas is not yet understood, but it is known that they are not related to drugs or medications that may have been taken during pregnancy, nor are they related to any known environmental exposures that may have occurred during that time. Rarely, in some families multiple family members over several generations have been affected, and this is related to a gene abnormality.

Abdominal wall lesions can be nontumorous or tumorous. Nontumorous lesions include congenital lesion, abdominal wall hernia, inflammation and infection, vascular lesions or miscellanous conditions [8].

Congenital hemangiomas can be classified into two subtypes: rapidly involuting congenital hemangioma and non-involuting congenital hemangioma. On ultrasonography these lesions are usually seen as welldefined hypoechoic masses and appear diffusely vascular [9].

In the present case, the initial diagnosis of a wall abdominal hemangioma was made on ultrasound examination. 3D Power Doppler HD ultrasound examination was an appropriate initial diagnostic modality. On subsequent examinations the size of the hemangioma remained stable during pregnancy.

This case suggests that the early prenatal ultrasound diagnosis was very useful in the management, treatment and prognosis of a giant abdominal wall hemangioma. Treatment is dependent upon both the stage of growth of the lesion, the presence of complications, and emotional needs and considerations. Observation, laser therapy, drug therapy, and surgical removal are the four most common management options. In some patients, a combination of several of these treatments may be used over a period of time [10].

In this case, after specific investigations in the neonatal care unit the baby was referred for surgical treatment. Surgery was a success and the baby came for the routine 6 months check up.

Funding: Nil, Conflict of interest: None initiated, Permission from IRB: Yes

\section{References}

1. Mulliken JB, Young A: Vascular Birthmarks: Hemangiomas and Malformations. Philadelphia, PA, WB Saunders, 1988.

2. Jennifer J. Marler, Steven J. Fishman, Joseph Upton, Patricia E. Burrows, Harriet J. Paltiel, Russell W. Jennings, and John B. Mulliken. Prenatal Diagnosis of Vascular Anomalies. Journal of Pediatric Surgery, Vol 37, No 3, 2002: pp 318-326.

3. Goldberg SR, Halvorsen RA, Neifeld JP. Vascular tumors of the abdominal wall. Am J Surg. 2004 Apr;187(4):553-6.

4. Shah PP, Dubhashi SP, Choudhary K. Anterior abdominal wall haemangioma with inguinal extension. $\mathbf{J}$ Clin Diagn Res. 2014 Nov;8(11):ND15-6. doi: 10.7860/JCDR/2014/9781.5190. Epub 2014 Nov 20.

5. Ojili, Vijayanadh et al. Abdominal Hemangiomas: A Pictorial Review of Unusual, Atypical, and Rare Types. Canadian Association of Radiologists Journal, Volume 64, Issue $1,18-27$. 
6. Maynor CH, Hertzberg BS, Kliewer MA, Heyneman LE, Carroll BA. Antenatal ultrasonographic diagnosis of abdominal wall hemangioma: potential to simulate ventral abdominal wall defects. J Ultrasound Med. 1995 Apr;14(4):317-9.

7. Albu, C., Albu, D. and Oncescu, A. Prenatal ultrasound diagnosis and follow up treatment of a giant lateral abdominal wall hemangioma. Ultrasound Obstet Gynecol, 42: 139.

8. Y.-W. Kim1, J. H. Yoon2, S. S. Cha2 ; 1 Yangsan/KR, 2 Busan/KR. Abdominal wall, abdominl wall. disease, abdominal wall, mas. 10.1594/ecr2010/C1671.
9. Loureiro T., Cunha M., Jesus J. M., Beires J., Montenegro N. Congenital abdominal hemangioma: three-dimensional power Doppler imaging and volume acquisition in the assessment of tumor vasculature. Ultrasound Obstet Gynecol 2008; 31: 593-596.

10. Hosono S, Ohno T, Kimoto H, Nagoshi R, Shimizu M, Nozawa M, Fuyama Y, Kaneda T, Moritani T, Aihara T. Successful transcutaneous arterial embolization of a giant hemangioma associated with high-output cardiac failure and Kasabach-Merritt syndrome in a neonate: a case report. J Perinat Med. 1999;27(5):399-403.

\section{How to cite this article?}

Dinu-Florin Albu, Cristina-Crenguta Albu, Andrei Oncescu, Stefan-Dimitrie Albu. Early prenatal ultrasonographic diagnosis and follow up treatment of a giant abdominal hemangioma: a rare case report. Int J Med Res Rev 2016;4(10):1764-1767.doi:10.17511/ijmrr. 2016.i10.09. 